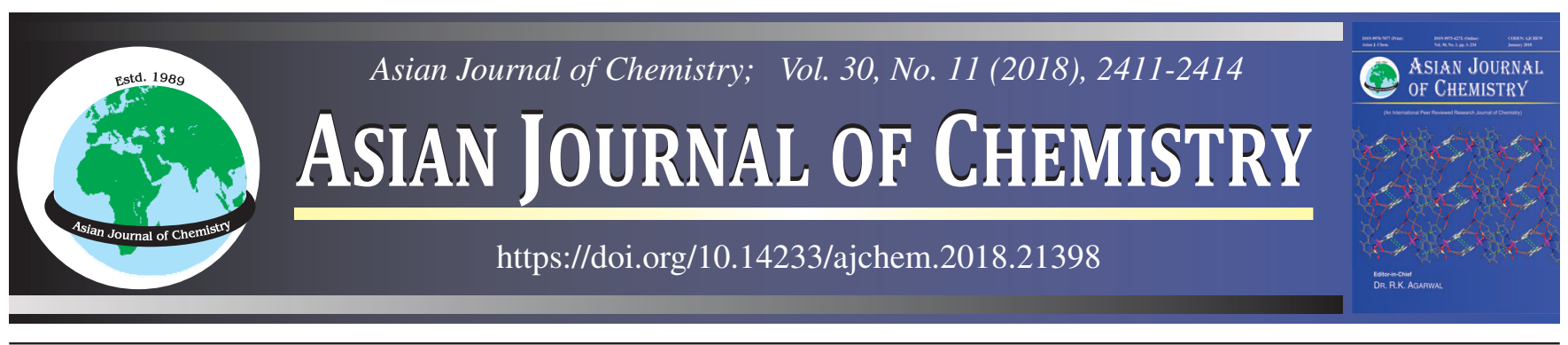

\title{
Synthesis of 5-Hydroxy-4-methoxy- $\alpha$-methyl-(1,2-benzobutane sultone) from Eugenol and Eugenil Acetate
}

\section{I.M. Sudarma*, L. Supiani, A. Syafitri, W.K. Hidayati, H. Oltantia and M.G. Darmayanti}

Department of Chemistry, Faculty of Mathematic and Natural Sciences, University of Mataram, Kota Mataram 83115, Indonesia

*Corresponding author: Fax: +62 370 648508; Tel: +62 370 646506; E-mail: sud_arma@yahoo.co.id

\begin{abstract}
The purpose of this study was to develop an efficient synthesis route to pharmacologically interesting sultone derivatives from readily accessed natural products. Synthetic approach of 5-hydroxy-4-methoxy- $\alpha$-methyl-(1,2-benzobutane sultone) via eugenol (1) produced only in moderate yield (64\%). On the other hand synthetic approach via eugenil acetate (2) gave 5-hydroxy-4-methoxy- $\alpha$-methyl-(1,2benzobutane sultone) in high yield (96\%). Eugenol approach involved only one step reaction due to direct reaction of eugenol with chlorosulfonic acid but in eugenil acetate approach involved two-step reactions due to its preparation of eugenol before reaction with chlorosulfonic acid. Eugenil acetate was prepared smoothly in good yield by esterification of phenolic group of eugenol with acetic anhydride in the presence of sodium bicarbonate. A variety of bicarbonate catalysts such as $\mathrm{NaHCO}_{3}, \mathrm{Na}_{2} \mathrm{CO}_{3}$ and $\mathrm{K}_{2} \mathrm{CO}_{3}$ were investigated in O-acetylation of eugenol to afford eugenil acetate (84\%), (72\%) and (88\%), respectively. Structures of all the products have been established by spectral and GC-MS analysis data.
\end{abstract}

Keywords: Comparison reaction, Eugenol, Eugenil acetate, Cyclic sulfonic ester, Sultone, Markovnikov.

\section{INTRODUCTION}

Eugenol (4-allyl-2-methoxyphenol) (1), a constituent of clove, has been used as a fine chemical for further chemical transformation [1-4]. Eugenol (1) has three reactive functional groups namely: alcohol as a phenol, phenyl and alkene as an allyl. These reactive functional groups can compete each other and will disturb further reaction such as on reaction of eugenol with chlorosulfonic acid to form sultone derivative.

In continuation of our work to increase the yield of sultone derivative (3), which previously prepared directly from eugenol, synthesis of this compound via Markovnikov addition of chlrosulfonic acid to eugenil acetate (2) was reported. This synthesis involved two steps reaction: firstly direct protection of phenolic group of eugenol by acetic anhydride to form eugenil acetate and secondly Markovnikov addition of chlorosulfonic acid to eugenil acetate.

Phenols are potentially reactive towards electrophilic aromatic substitution. This is because the hydroxy group, $-\mathrm{OH}$, is a strongly activating, ortho- or para- directing substituent. Protection of phenols is one of the most common synthetic strategies utilized to mask hydroxyl functionalities during multistep synthetic procedures. In addition, O-acetylation procedures are widely employed for the protection and purification of various natural and synthetic products. Solventfree O-acetylation of alcohols, phenols and thiols using catalytic amounts of sodium acetate trihydrate gave good yields [5]. A variety of primary alcohols and phenols were reacted with acetic anhydride at room temperature in the presence of sodium bicarbonate to produce corresponding esters and eugenol was reacted with acetic anhydride at room temperature in the presence of sodium bicarbonate to produce corresponding esters in good to excellent yields [6]. A series of ecofriendly solid acid catalysts including: Preyssler, Wells-Dowsen and Keggin HPAs have been used as catalysts for acetylation of alcohols, phenols and salicylic acid with acetic anhydride [7]. Acylation of eugenol with $\mathrm{Ac}_{2} \mathrm{O} / \mathrm{Py} / \mathrm{DMAP}$ in dichloromethane at room temperature gave eugenil acetate in high yield (98\%) [8].

Eugenil acetate (4-allyl-2-methoxyphenyl acetate) has an asymmetrically substituted alkenes which can undergoes Markovnikov addition by strong acid such as chlorosulfonic

This is an open access journal, and articles are distributed under the terms of the Creative Commons Attribution-NonCommercial 4.0 International (CC BY-NC 4.0) License, which allows others to copy and redistribute the material in any medium or format, remix, transform, and build upon the material, as long as appropriate credit is given and the new creations are licensed under the identical terms. 
acid $\left(\mathrm{H}-\mathrm{O}-\mathrm{SO}_{2} \mathrm{Cl}\right)$, which states that when a strong acid is added to an asymmetrically substituted alkene, the major product results from the addition of hydrogen atom to double-bonded carbon that is attached to more hydrogen atoms [9]. Furthermore, a sultone derivative (3) was formed from this addition. Sultones are heterocyclic compounds and are internal esters of the corresponding hydroxy sulfonic acids [10]. Sultones are reactive intermediates having commercial applications in detergents, polymers, antistatics and other industrial applications [11].

In the present work, an effort for design and synthesis of biologically active sultone derivative from eugenol and eugenil acetate will be discussed.

\section{EXPERIMENTAL}

The material used included: clove, dichloromethane, hexane, methanol, acetonitrile, acetate anhydride, ethanol, sodium hydroxide pellet, hydrochloric acid, sodium hydrogen carbonate anhydrous, ethyl acetate, sodium carbonate anhydrous, chlorosulfonic acid, analytical thin layer chromatography, silica gel chromatography.

General procedure: Dried clove buds were ground into fine particles (powder) for extraction. Clove powder (150 g) were percolated with dichloromethane $(1 \mathrm{~L})$ and stored away from light for $2 \times 24 \mathrm{~h}$. The result then filtered and the filtrate was evaporated with rotary evaporator to obtain the brownish clove oil (32 g; $21 \%)$.

Isolation of eugenol (1): Clove oil (21 $\mathrm{g}$ ) were dissolved in dichloromethane $(65.7 \mathrm{~mL})$. The mixture was added with $\mathrm{NaOH}$ (5.36 g), which had been dissolved with $\mathrm{H}_{2} \mathrm{O}(39 \mathrm{~mL})$. Mixture was stirred with magnetic stirrer for $60 \mathrm{~min}$ in room temperature. Two layers were formed where the aqueous phase in the top layer was separated from the organic phase in the bottom layer. The aqueous phase that contains eugenol salt was acidified with concentrated $\mathrm{HCl}$ to $\mathrm{pH} 3$. The organic layer was then separated from the aqueous layer with separation funnel. The remaining aqueous layer then extracted with dichloromethane ( $15 \mathrm{~mL}, 3 \mathrm{x})$. The crude eugenol then filtered with dichloromethane: $n$-hexane (1:1) through dilica gel mixture and evaporated with rotary evaporator to afford yellowish oil $(18.3 \mathrm{~g}, 83.7 \%)$. The oil was analyzed by TLC. TLC analyses showed eugenol sample $\mathrm{R}_{\mathrm{f}} 0.72$ and eugenol standard $\mathrm{R}_{\mathrm{f}} 0.72$ (eluent: $\mathrm{CH}_{2} \mathrm{Cl}_{2}$ ).

Synthesis of eugenil acetate (2): This reaction was conducted by adopting method from Lugemwa et al. [6]. A mixture of eugenol ( $1 \mathrm{~g}, 6.10 \mathrm{mmol})$, acetate anhydride $(3 \mathrm{~g}, 30 \mathrm{mmol})$, $\mathrm{K}_{2} \mathrm{CO}_{3}(1 \mathrm{~g}, 12 \mathrm{mmol})$, ethyl acetate $(75 \mathrm{~mL})$ was stirred at room temperature for the $24 \mathrm{~h}$. The progress of the reaction was monitored by TLC. After completion of the reaction, the mixture was filtered and the filtrate was evaporated by rotary evaporator. The residue was added dichloromethane $(25 \mathrm{~mL})$ and water $(10 \mathrm{~mL})$ and the phases separated. The organic layer was dried $\left(\mathrm{Na}_{2} \mathrm{CO}_{3}\right)$ and concentrated to afford syrup (1.1 g, $5.34 \mathrm{mmol}, 87.5 \%)$. The syrup was analyzed by TLC and GC-MS. TLC analyses showed eugenil acetate sample $\mathrm{R}_{\mathrm{f}} 0.78$ (eluent: $\mathrm{CH}_{2} \mathrm{Cl}_{2}$ ). GC-MS: $\mathrm{M}^{+} \cdot 206$, cal for $\mathrm{C}_{12} \mathrm{H}_{14} \mathrm{O}_{3}$, major fragments : 164 (base peak), 149, 131, 121, 103, 91, 77.

Synthesis of cyclic sulfonic ester or sultone derivative (3): This reaction was conducted by adopting method from
Sudarma et al. [1]. To stirred solution of eugenil acetate (2) $(500 \mathrm{mg}, 2.43 \mathrm{mmol})$ in dichloromethane $(25 \mathrm{~mL})$ was added chlorosulfonic acid $(2.5 \mathrm{~mL})$ drop by drop. The solution was stirred at room temperature for $30 \mathrm{~min}$ then refluxed for $15 \mathrm{~min}$. The solution was evaporated and water $(15 \mathrm{~mL})$ then added, basified to $\mathrm{pH} 8$ with $1 \mathrm{M}$ sodium hydroxide, then extracted with dichloromethane. The organic phase was dried and evaporated to dryness to give an amorphous brown solid (96\%). Compound (3), GC-MS: $\mathrm{M}^{+} .244$, cal for $\mathrm{C}_{10} \mathrm{H}_{12} \mathrm{SO}_{5}$ Major fragments: 200, 183, 165, 151, 136 (base peak). IR (film), $\left.v_{\max }, \mathrm{cm}^{-1}\right): 3232(\mathrm{O}-\mathrm{H}), 3084(\mathrm{C}=\mathrm{CH}-\mathrm{Ar}), 2936,2829,1399$, 1327, 1260 (C-O), 1127 (C-O), 1066, 999, 912, 764. ${ }^{1} \mathrm{H}$ NMR $\left(400.1 \mathrm{MHz}, \mathrm{CDCl}_{3}\right): \delta 1.62\left(3 \mathrm{H}, \mathrm{d}, J 6.6 \mathrm{~Hz},-\mathrm{CH}_{3}\right) ; 2.16$ $(1 \mathrm{H}, \mathrm{s}, \mathrm{OH}) ; 2.85-2.31\left(2 \mathrm{H}, \mathrm{m},-\mathrm{CH}_{2}-\right) ; 3.93\left(3 \mathrm{H}, \mathrm{s},-\mathrm{OCH}_{3}\right)$; $5.20(1 \mathrm{H}, \mathrm{m},-\mathrm{CH}-) ; 6.60(1 \mathrm{H}, \mathrm{s}, \mathrm{ArH}) ; 7.33(1 \mathrm{H}, \mathrm{s}, \mathrm{ArH}) .{ }^{13} \mathrm{C}$ NMR (400.1 MHz, $\left.\mathrm{CDCl}_{3}\right): \delta 21.3\left(-\mathrm{CH}_{3}\right) ; 35.6\left(-\mathrm{CH}_{2}\right) ; 56.4$ $(-\mathrm{CH}-) ; 110.1(\mathrm{ArCH}) ; 110.6(\mathrm{ArCH}) ; 126.8(\mathrm{ArC}) ; 127.2$ $(\mathrm{ArC}) ; 145.4$ (ArC); 150.1 (ArC).

\section{RESULTS AND DISCUSSION}

Eugenol (1) was extracted and isolated from clove oil in good yield $(83.7 \%)$. The presence of -OH group as a phenol in eugenol (1) is potentially decreased the yield of sultone because this functional group is very reactive towards electrophilic aromatic substitution, oxidation, etc. To increase the yield of sultone, presumably the -OH group of eugenol (1) has to be protected. Protection of hydroxyl is one common synthetic strategies utilized to mask hydroxyl functionalities during further step synthetic procedures. Esterification is one way to protect the $-\mathrm{OH}$ of eugenol. A varies of catalyst were employed to increase the yield of esterification of eugenol by acetate anhydride. Eugenol was reacted with acetic anhydride at room temperature in the presence of bicarbonate catalyst to produce corresponding esters or eugenil acetate (2) in moderate to good yield (Table-1).

\section{TABLE-1 ACETYLATION OF EUGENOL (1) TO BE EUGENIL ACETATE (2)}

\begin{tabular}{clc}
\hline No. & \multicolumn{1}{c}{ Catalyst and its condition } & $\begin{array}{c}\text { Yield of } \\
\text { compd. 2 (\%) }\end{array}$ \\
\hline 1 & $\mathrm{NaHCO}_{3} /\left(\mathrm{CH}_{3} \mathrm{CO}\right)_{2} \mathrm{O}$, ethyl acetate, r.t., 24 h & 84 \\
2 & $\mathrm{NaHCO}_{3} /\left(\mathrm{CH}_{3} \mathrm{CO}\right)_{2} \mathrm{O}$, acetonitrile, r.t., 24 h & 72 \\
3 & $\mathrm{Na}_{2} \mathrm{CO}_{3} /\left(\mathrm{CH}_{3} \mathrm{CO}\right)_{2} \mathrm{O}$, ethyl acetate, r.t., 24 h & 88 \\
4 & $\mathrm{~K}_{2} \mathrm{CO}_{3} /\left(\mathrm{CH}_{3} \mathrm{CO}\right)_{2} \mathrm{O}$, ethyl acetate, r.t., 24 h & 88 \\
\hline
\end{tabular}

It has been reported that eugenol (1) reacted with chlorosulfonic acid to form sultone derivative (3) in moderate yield (64\%) [1]. After protection of the-OH group of eugenol (1) to be eugenil acetate (2) and further reaction with chlorosulfonic acid, presumably will afford sultone derivative (2c), but this hypothesis was not correct. These reaction gave the same product as reaction of eugenol (1) with chlorosulfonic acid (Scheme-I).

In the first stage, the chemical basis for Markovnikov's rule is the transformation of the most stable carbocation during the addition process (Scheme-II) [1,9]. The addition of the hydrogen from $\mathrm{H}-\mathrm{OSO}_{2} \mathrm{Cl}$ to one carbon atom in the double bond of allyl group of eugenil acetate (2) creates a positive 


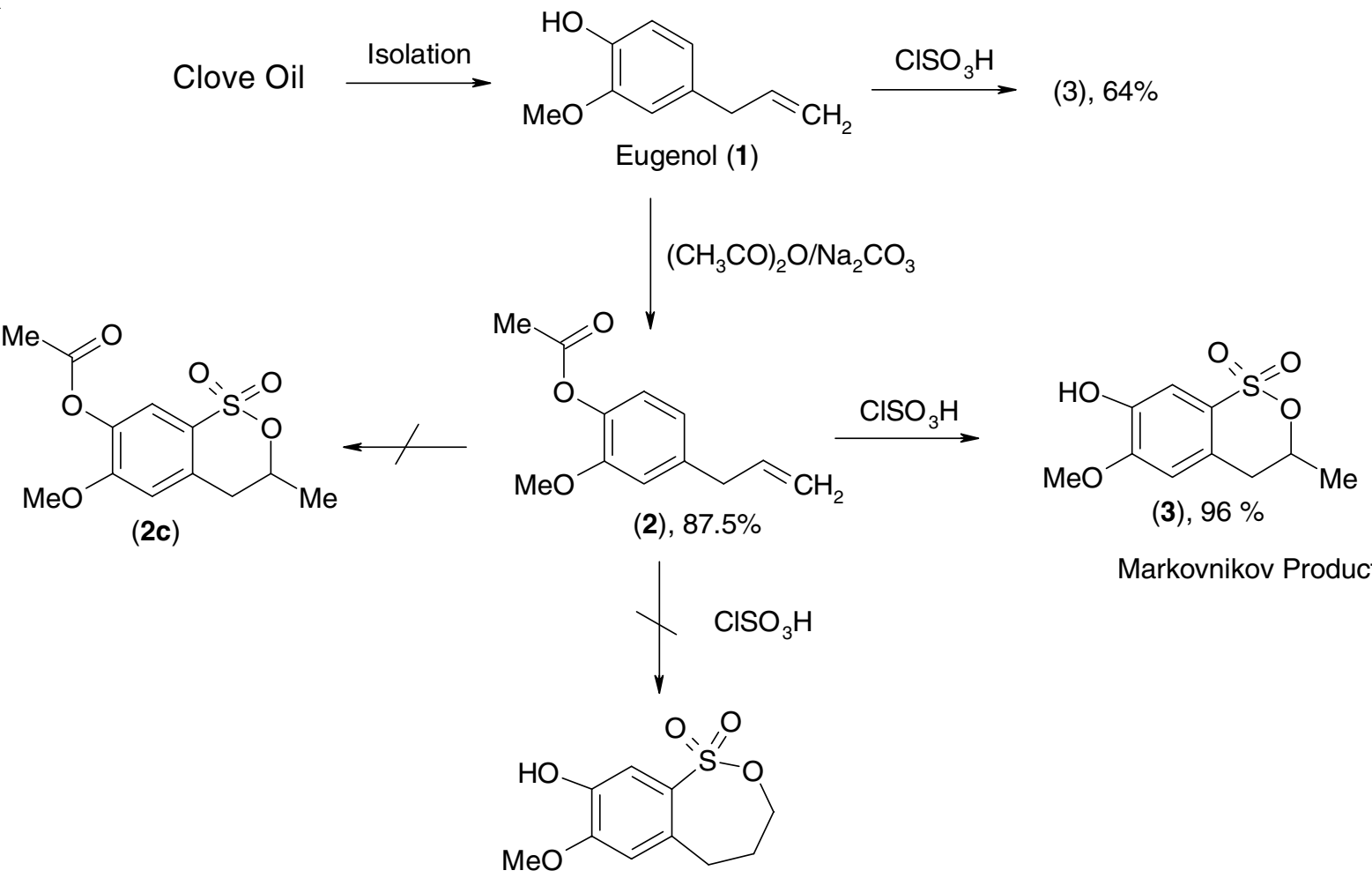

(4)

Anti-Markovnikov Product

Scheme-I: Synthesis route of sultone derivative (3) from eugenol (1) and eugenil acetate (2)<smiles></smiles><smiles>O=S(=O)(Cl)O[In]</smiles><smiles></smiles><smiles>COc1cc2c(cc1O)S(=O)(=O)OC(C)C2</smiles>

(3)<smiles>COc1cc2c(cc1OCCCl)S(=O)(=O)OC(C)C2</smiles>

(2c)<smiles>COc1cc(CCS(=O)(=O)Cl)c(CC(OS(C)(=O)=O)C(C)(C)C)cc1OC</smiles>

Scheme-II: Formation mechanism of sultone derivative (3) from eugenil acetate

charge on the other carbon, forming a carbocation intermediate (2a). The more substituted the carbocation the more stable it is, due to induction and hyperconjugation effects [9]. The carbocation $\mathrm{C}^{\prime}$ ' is more stable than carbocation $\mathrm{C}^{\prime}$ ' and $-\mathrm{OSO}_{2} \mathrm{Cl}$ will attack the carbocation $\mathrm{C} 2$ ' leads to the formation of intermediate (2b). However, the other less substituted $\mathrm{C} 1$ ' or less stable carbocation $\mathrm{C} 1$ ' will still be formed and will proceed to form the minor product with the opposite attachment of ${ }^{-} \mathrm{OSO}_{2} \mathrm{Cl}$ but such intermediate is not detected from the GCMS and NMR analyses [1]. In the second stage of the reaction, a base donates electrons to the hydrogen atom and generated the losses of $\mathrm{HCl}$ to afford cyclic product (2c). Final stage, cleavage of ester by $\mathrm{HCl}$ produced sultone derivative (3).
On the basis of spectroscopic evidence and mechanistic considerations, the structure of sultone derivative (3) was proposed for Markovnikov product and excluded the AntiMarkovnikov product (4) as proposed in Scheme-I. Additional methyl group as a doublet at $\delta 1.58$ in ${ }^{1} \mathrm{H}$ NMR spectrum gave appropriate information about cyclic sulfonic ester derivative (3) compare to (4). This analysis was supported by ${ }^{13} \mathrm{C}$ NMR and DEPT, which gave 4 quaternary carbons, 3 methine carbons, 1 methylene carbon and 2 methyl carbons. Generally, the ${ }^{1} \mathrm{H}$ NMR spectrum supported the proposed structure (3).

\section{Conclusion}

Reaction of eugenol (1) with chlorosulfonic acid gave cyclic sulfonic ester or sultone derivative (3) in moderate yield 
(64\%), on the other hand reaction of eugenil acetate (2) with chlorosulfonic acid also gave sultone derivative (3) in high yield $(96 \%)$. Both reactions occurred via Markovnikov rule.

\section{ACKNOWLEDGEMENTS}

The authors thank Indonesian Ministry of Research, Technology and Higher Education (Kementerian Riset, Teknologi, dan Pendidikan Tinggi) through "Hibah Kompetensi" for financial support.

\section{CONFLICT OF INTEREST}

The authors declare that there is no conflict of interests regarding the publication of this article.

\section{REFERENCES}

1. I.M. Sudarma, E. Yuanita and I.W. Suana, Indo. J. Chem., 13, 181 (2013); https://doi.org/10.22146/ijc.21303.

2. M.R.C. Raja, V. Srinivasan, S. Selvaraj and S.K. Mahapatra, Pharm. Anal. Acta, 6, 1000367 (2015);

https://doi.org/10.4172/2153-2435.1000367.
3. S.K. Mahapatra and S. Roy, Asian Pac. J. Trop. Med., 7, S391 (2014); https://doi.org/10.1016/S1995-7645(14)60264-9.

4. R. Mahboub and F. Memmou, Nat. Prod. Res., 29, 966 (2015); https://doi.org/10.1080/14786419.2014.958738.

5. M.M. Mojtahedi and S. Samadian, J. Chem., Artcle ID 642479 (2013); https://doi.org/10.1155/2013/642479.

6. F.N. Lugemwa, K. Shaikh and E. Hochstedt, Catalysts, 3, 954 (2013); https://doi.org/10.3390/catal3040954.

7. M.M. Heravi, F.K. Behbahani and F.F. Bamoharram, ARKIVOC, 123 (2007); https://doi.org/10.3998/ark.5550190.0008.g13.

8. H. Carrasco A, L. Espinoza C, V. Cardile, C. Gallardo, W. Cardona, L. Lombardo, K. Catalán, M. Cuellar and A. Russo, J. Braz. Chem. Soc., 19, 543 (2008); https://doi.org/10.1590/S0103-50532008000300024

9. A.E. Strom and J.F. Hartwig, J. Org. Chem., 78, 8909 (2013); https://doi.org/10.1021/jo401498w.

10. B. Li, W. Yan, C. Zhang, Y. Zhang, M. Liang, F. Chu, Y. Gong, B. Xu, P. Wang and H. Lei, Molecules, 20, 4307 (2015); https://doi.org/10.3390/molecules20034307.

11. S. Mondal, Chem. Rev., 112, 5339 (2012); https://doi.org/10.1021/cr2003294. 